\title{
Trichoderamides A and B, a pair of stereoisomers from the plant endophytic fungus Trichoderma gamsii
}

\author{
Gang Ding ${ }^{1,2,5}$, Lin Chen ${ }^{1,5}$, Cao Zhou ${ }^{1}$, Jia Hong-Mei ${ }^{1}$, Yue-Tao Liu ${ }^{1}$, Xing Chang ${ }^{1}$, Bo Song ${ }^{1}$, \\ Xing-Zhong $\mathrm{Liu}^{3}$, Yu-Cheng $\mathrm{Gu}^{4}$ and Zhong-Mei Zou ${ }^{1}$
}

The Journal of Antibiotics (2015) 68, 409-413; doi:10.1038/ja.2015.1; published online 4 February 2015

Owing to the fact that the combinatory chemistry could not meet the need of structural diversity of drug leads in industry, ${ }^{1}$ and new resistant pathogens are currently becoming rampant, there is a revival of interest in the discovery of new natural products from different resource, especially collected from unique biotopes. Endophytic fungi, a special group of microbe inhabiting normal tissues of the host plants without causing apparent pathogenic symptoms, have been demonstrated to be one of the hot topics in the field of natural products. In our previous reports, a series of cytochalasans alkaloids with unique skeleton characteristics were obtained from the plant endophytic fungus 'talented strain' (means to produce diverse skeleton secondary metabolites) Trichoderma gamsii (Figure 1). ${ }^{2-6}$ In order to determine novel/new bioactive secondary metabolites from this endophytic fungus, trichoderamides A (1) and B (2), a pair of unique stereoisomers originated from the PKS-NRPS hybrid pathway, together with two new compounds trichodenols A (3) and B (4), and a new natural product $N$-formyl-L-tyrosine methyl ester $(5)^{7}$ were obtained (Figure 2) from the extract of new fermentation. In this note, the structural elucidation and bioactivities of these compounds are present.

The culture of T. gamsii was isolated from the traditional Chinese medicinal plant Panax notoginseng (BurK.) F.H. Chen. The isolate was identified on the basis of the sequence (Genbank Accession No. JF964996) obtained by the analysis of the internal transcribed spacer region of the rDNA. The fungal strain was cultured on slants of potato dextrose agar at $25^{\circ} \mathrm{C}$ for 10 days. The agar plugs were used to inoculate in Fernbach flasks $(500 \mathrm{ml})$, each containing $80 \mathrm{~g}$ of rice, and incubated at $25^{\circ} \mathrm{C}$ for 40 days. The fermented material was extracted with ethyl acetate ( 51 for four times). The solution was concentrated to dryness under vacuum to afford a crude extract $(50.0 \mathrm{~g})$, which was fractionated by silica gel column chromatography $(10 \times 100 \mathrm{~cm})$ using $\mathrm{CH}_{2} \mathrm{Cl}_{2}-\mathrm{MeOH}$ gradient elution. The fraction (644 mg) eluted with $\mathrm{CH}_{2} \mathrm{Cl}_{2}-\mathrm{MeOH}$ 100:4 was separated by Sephadex (LH-20) (Pharmacia, Uppsala, Sweden), column chromatography to afford five fractions
(E1-E4). Fraction E3 (20 mg) was purified by RP-HPLC (Lumtech, Berlin, Germany; YMC-Pack ODS-A column; $10 \mu \mathrm{m} ; 250 \times 10 \mathrm{~mm}$; $2 \mathrm{ml} \mathrm{min}^{-1}, 49 \% \mathrm{MeOH}$ in $\mathrm{H}_{2} \mathrm{O}$ for $40 \mathrm{~min}$ ) to afford trichoderamide $\mathrm{A}\left(1 ; 2 \mathrm{mg}, t_{\mathrm{R}} 28.5 \mathrm{~min}\right)$ and trichoderamide $\mathrm{B}\left(2 ; 2 \mathrm{mg}, t_{\mathrm{R}} 33.3 \mathrm{~min}\right)$; fraction E2 (40 mg) was purified by RP-HPLC (Lumtech; YMC-Pack ODS-A column; $10 \mu \mathrm{m} ; 250 \times 10 \mathrm{~mm} ; 2 \mathrm{ml} \mathrm{min}^{-1}, 49 \% \mathrm{MeOH}$ in $\mathrm{H}_{2} \mathrm{O}$ for $20 \mathrm{~min}$ ) afforded trichodenol A (3; $\left.2 \mathrm{mg}, t_{\mathrm{R}} 15.4 \mathrm{~min}\right)$ and trichodenol B $\left(4 ; 6 \mathrm{mg}, t_{\mathrm{R}} 17.3 \mathrm{~min}\right)$; fraction E1 (30 mg) was purified by RP-HPLC (Lumtech; YMC-Pack ODS-A column; $10 \mu \mathrm{m}$; $250 \times 10 \mathrm{~mm} ; 2 \mathrm{ml} \mathrm{min}^{-1}, 51 \% \mathrm{MeOH}$ in $\mathrm{H}_{2} \mathrm{O}$ for $20 \mathrm{~min}$ ) afforded $\mathrm{N}$-formyl-L-tyrosine methyl ester $\left(5 ; 4 \mathrm{mg}, t_{\mathrm{R}} 13.2 \mathrm{~min}\right)$.

Optical rotations were measured on a Perkin-Elmer 241 Polarimeter (Perkin-Elmer, Bruker, Billerica, MA, USA), ${ }^{1} \mathrm{H}$ and ${ }^{13} \mathrm{C}$ NMR data were acquired using Bruker 600 and Varian Inova 600 spectrometers using solvent signals (DMSO- $d_{6} ; \delta_{\mathrm{H}} 2.49 / \delta_{\mathrm{C}} 39.5$ ) as references. The HMQC and HMBC experiments were optimized for 145.0 and $8.0 \mathrm{~Hz}$, respectively. HRESIMS data were acquired using a LTQ Orbitrap XL Mass Spectrometer (Thermo, Waltham, MA, USA).

Trichoderamide A (1) was isolated as a colorless oil, $[\alpha]_{\mathrm{D}}^{22}=-233.5$ ( $c=0.1$, methanol). Its molecular formula was determined as $\mathrm{C}_{16} \mathrm{H}_{19} \mathrm{NO}_{5}$ (8 degrees of unsaturation) by TOF-ESI-MS spectrum data, which showed a pseudomolecular ion at $m / z 328.1152[\mathrm{M}+\mathrm{Na}]^{+}$. The ${ }^{1} \mathrm{H},{ }^{13} \mathrm{C}$ NMR and HMQC NMR spectra data of 1 (Table 1) displayed a methyl group, a methoxyl, three methylene units, two methines, three carbonyl groups and one para-substituted phenyl ring. The ${ }^{1} \mathrm{H}-{ }^{1} \mathrm{H}$ COSY correlations revealed four isolated proton spin systems corresponding to C-2-C-3, C-5-C-6, C-7-C-8 and C-11$\mathrm{C}-13$ fragments (Figure 3 ), and the remaining connectivity was obtained by HMBC correlations (Figure 3). The correlation of 4-OH with C-3, C-4 and C-5 implied the hydroxyl was attached to C-4; HMBC correlations from $7-\mathrm{H}_{2}$ to C-1, C-2 and C-6 confirmed the C-7-C-8 unit was connected with C-1; the methyl 3-(4-hydroxyphenyl)-propionate unit was established by the HMBC

${ }^{1}$ Institute of Medicinal Plant Development, Chinese Academy of Medical Sciences and Peking Union Medical College, Beijing, P.R. China; ${ }^{2}$ State Key Laboratory of Bioactive Substance and Function of Natural Medicines, Institute of Materia Medica, Beijing, P.R. China; ${ }^{3}$ Institute of Microbiology, Chinese Academy of Sciences, Beijing, P.R. China and ${ }^{4}$ Syngenta Jealott's Hill International Research Center, Bracknell, UK

5These authors contributed equally to this work.

Correspondence: Professor Z-M Zou, Institute of Medicinal Plant Development, Chinese Academy of Medical Sciences and Peking Union Medical College, Maliawa North Road, 151, Beijing 100193, P.R. China.

E-mail: zmzou@implad.ac.cn

Received 25 July 2014; revised 16 December 2014; accepted 27 December 2014; published online 4 February 2015 


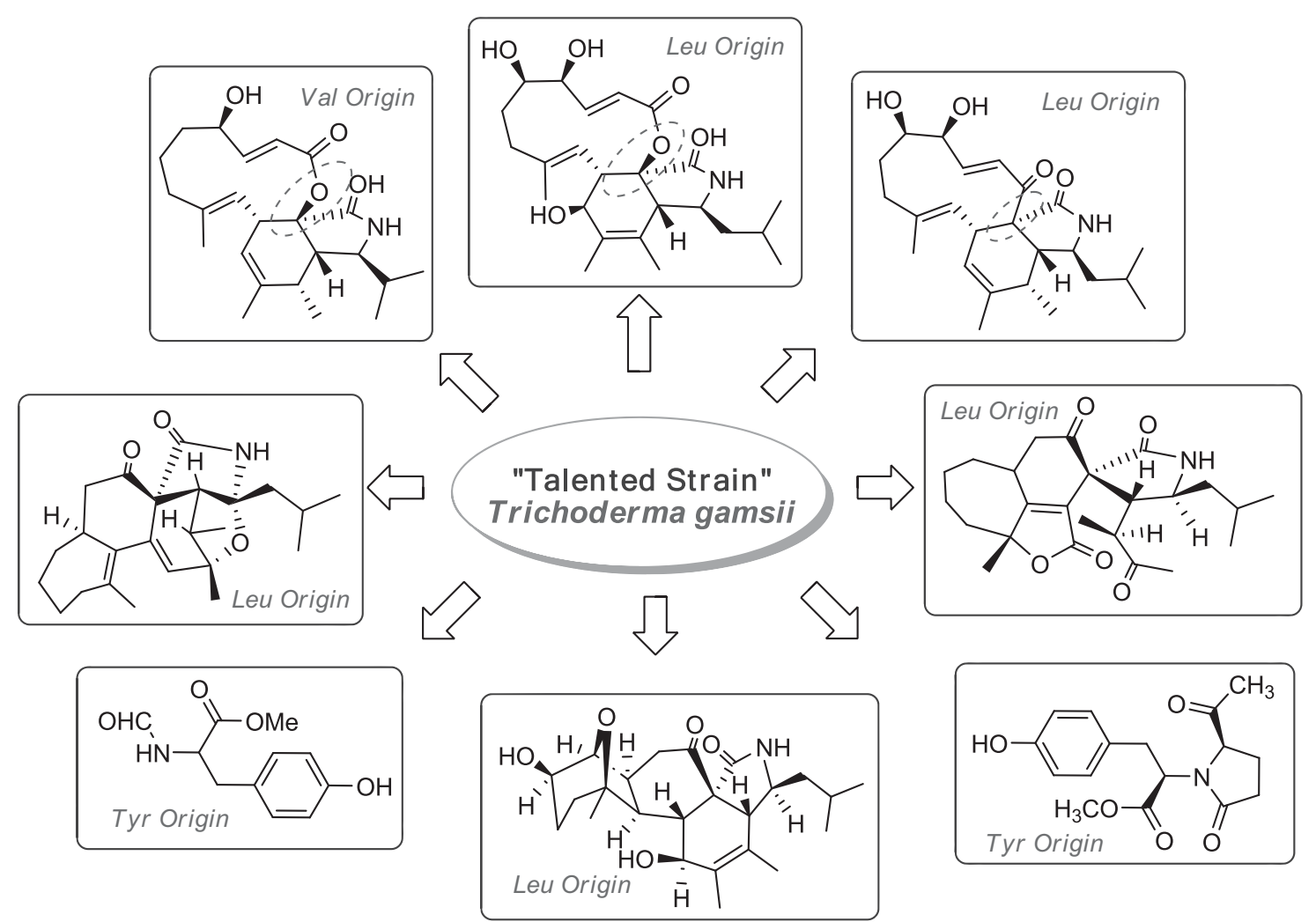

Figure 1 Alkaloids originated from diverse skeleton isolated from the 'talented strain' Trichoderma gamsii. A full color version of this figure is available at The Journal of Antibiotics journal online.<smiles>COC(=O)[C@H](Cc1ccc(O)cc1)N1C(=O)CC=C1C(C)=O</smiles><smiles>COC(=O)[C@H](Cc1ccc(O)cc1)N1C(=O)CC[C@H]1C(C)=O</smiles><smiles>COC(=O)C(Cc1ccc(O)cc1)NC=O</smiles><smiles>CC(O)C(O)CCC(=O)OCCc1ccc(O)cc1</smiles><smiles>C[C@@H](O)C(=O)CCC(=O)OC[Te]c1ccc(O)cc1</smiles>

Figure 2 Structures of compounds $\mathbf{1 - 5 .}$

correlations from $\mathrm{H}-8$ to $\mathrm{C}-9$ and $9-\mathrm{OCH}_{3}$ to $\mathrm{C}-9$; the correlations of 15- $\mathrm{CH}_{3}$ with $\mathrm{C}-13$, C-14, of $\mathrm{H}-13$ and $\mathrm{H}_{2}-11$ with $\mathrm{C}-10$ implied the presence of a 5-acetylpyrrolidin-2-one moiety; the HMBC correlations of $\mathrm{H}-8$ with $\mathrm{C}-10$ and $\mathrm{C}-13$, in return, of $\mathrm{H}-13$ with C-8 indicated that a nitrogen atom was attached to C-8, C-10 and C-13, respectively. Thus, the planar structure of $\mathbf{1}$ was assigned.
Trichoderamide B (2), obtained as a colorless oil, $[\alpha]_{\mathrm{D}}^{22}=+274.5$ ( $c=0.03$, methanol). was assigned as $\mathrm{C}_{16} \mathrm{H}_{19} \mathrm{NO}_{5}$ on the basis of its positive HRESIMS results $\left(\mathrm{m} / z 328.1154[\mathrm{M}+\mathrm{Na}]^{+}\right)$. Compound 2 possessed the similar ${ }^{1} \mathrm{H}$ and ${ }^{13} \mathrm{C}$ NMR data (Table 1) as those of $\mathbf{1}$ except the chemical shift value difference between $\mathrm{H} / \mathrm{C}-8\left(\delta_{\mathrm{H}} 4.37 / \delta_{\mathrm{C}}\right.$ 57.2 in 1 and $\delta_{\mathrm{H}} 4.76 / \delta_{\mathrm{C}} 54.7$ in 2$)$ and $\mathrm{H} / \mathrm{C}-13\left(\delta_{\mathrm{H}} 3.81 / \delta_{\mathrm{C}} 65.7\right.$ in 1 
and $\delta_{\mathrm{H}} 4.59 / \delta_{\mathrm{C}} 62.5$ in 2) in those two compounds (Table 1). Owing to the fact that $\mathrm{N}$-formyl-L-tyrosine methyl ester (5) was also isolated from this fungus, the stereocenter of C-8 in $\mathbf{1}$ and $\mathbf{2}$ was postulated the same as that of $\mathbf{5}$ on the basis of the similar biosynthetic pathway. Thus, accounting for the different NMR spectra and biosynthesis, the stereochemistry of C-13 in 1 and 2 was implied to be different.

The relative configurations of $\mathbf{1}$ and $\mathbf{2}$ were determined by NOED spectra and analyzed by Minimized Energy in the ChemBio 3D Ultra Software (Cambridge, MA, USA) in detail. In the NOED spectra, the irradiation of H-8 obviously observed the enhancement of $\mathrm{H}-2 / 6$, $\mathrm{H}-7 \mathrm{a}$ and $\mathrm{H}-13$, in turn, irradiation of $\mathrm{H}-13$ observed the enhancement of $\mathrm{H}-8, \mathrm{H}-12 \mathrm{a} / \mathrm{b}$ and $\mathrm{Me}-15$ in 1 , whereas in 2 , irradiation of H-8 observed the enhancement of $\mathrm{H}-2 / 6$ and $\mathrm{H}-7 \mathrm{a} / \mathrm{b}$, in turn, irradiation of $\mathrm{H}-13$ observed the enhancement of $\mathrm{H}-7 \mathrm{~b}, \mathrm{H}-12 \mathrm{a}$ and Me-15 in 2 (Figure 4). This information suggested that $\mathrm{H}-8$ and $\mathrm{H}-13$ in 1 were close in space, whereas in $2, \mathrm{H}-8$ and $\mathrm{H}-13$ was opposite to each other on the corresponding 5 -acetylpyrrolidin-2-one ring system.

Table $1{ }^{1} \mathrm{H}(600 \mathrm{MHz})$ and ${ }^{13} \mathrm{C}$ NMR (150 MHz) spectroscopic data (DMSO- $d_{6}$ ) of trichoderamides A and B (1 and 2)

\begin{tabular}{|c|c|c|c|c|}
\hline \multirow[b]{2}{*}{ Pos } & \multicolumn{2}{|c|}{ Trichoderamide A (1) } & \multicolumn{2}{|c|}{ Trichoderamide $B$ (2) } \\
\hline & $\delta_{H}(\mathrm{~J}$ in $H z)$ & $\delta_{C}$, mult. & $\delta_{H}(\mathrm{~J}$ in $H z)$ & $\delta_{C}$, mult. \\
\hline 1 & - & 127.0, s & - & $126.5, \mathrm{~s}$ \\
\hline 2 & $6.93, \mathrm{~d}(8.4)$ & 129.9, d & $6.98, d(8.4)$ & 129.9, d \\
\hline 3 & $6.67, \mathrm{~d}(8.4)$ & $115.2, \mathrm{~d}$ & $6.65, \mathrm{~d}(8.4)$ & $115.1, \mathrm{~d}$ \\
\hline 4 & - & 156.0, s & - & $155.9, \mathrm{~s}$ \\
\hline 5 & $6.67, \mathrm{~d}(8.4)$ & $115.2, \mathrm{~d}$ & $6.65, \mathrm{~d}(8.4)$ & $115.1, \mathrm{~d}$ \\
\hline 6 & $6.93, \mathrm{~d}(8.4)$ & 129.9, d & $6.98, d(8.4)$ & 129.9, d \\
\hline $7 a$ & 2.90, dd $(14.4,7.8)$ & $34.0, \mathrm{t}$ & 2.99, dd $(14.4,7.8)$ & $34.0, \mathrm{t}$ \\
\hline $7 b$ & $2.85, \mathrm{dd}(14.4,7.8)$ & - & 2.81, dd $(14.4,7.8)$ & - \\
\hline 8 & $4.37, \mathrm{t}(7.8)$ & $57.2, \mathrm{~d}$ & $4.76, \mathrm{t}(7.8)$ & 54.7, d \\
\hline 9 & - & $170.2, \mathrm{~s}$ & - & $170.1, \mathrm{~s}$ \\
\hline 10 & - & $174.8, \mathrm{~s}$ & - & $174.4, \mathrm{~s}$ \\
\hline $11 a$ & $2.29, \mathrm{~m}$ & $28.7, \mathrm{t}$ & $2.14, \mathrm{~m}$ & $26.2, \mathrm{t}$ \\
\hline $11 b$ & $2.17, \mathrm{~m}$ & - & $2.05, \mathrm{~m}$ & - \\
\hline $12 a$ & $2.06, \mathrm{~m}$ & $22.1, \mathrm{t}$ & $2.03, \mathrm{~m}$ & $22.2, \mathrm{t}$ \\
\hline $12 b$ & $1.86, \mathrm{~m}$ & - & $1.89, \mathrm{~m}$ & - \\
\hline 13 & 3.81 , dd $(8.4,3.0)$ & $65.7, \mathrm{~d}$ & 4.59, dd $(8.4,3.0)$ & $62.5, \mathrm{~d}$ \\
\hline 14 & - & $207.3, \mathrm{~s}$ & - & $206.1, \mathrm{~s}$ \\
\hline $4-\mathrm{OH}$ & $9.28, \mathrm{~s}$ & - & $9.24, \mathrm{~s}$ & - \\
\hline $9-\mathrm{OCH}_{3}$ & $3.56, \mathrm{~s}$ & $51.8, \mathrm{q}$ & $3.50, \mathrm{~s}$ & $51.6, \mathrm{q}$ \\
\hline $15-\mathrm{CH}_{3}$ & $2.12, \mathrm{~s}$ & $26.0, \mathrm{q}$ & $2.12, \mathrm{~s}$ & $26.0, q$ \\
\hline
\end{tabular}

In theory, there existed four possible relative configurations of $\mathbf{1}$ and $\mathbf{2}$ ( $\mathbf{1} \mathbf{a}$ and $\mathbf{1 b}, \mathbf{2} \mathbf{a}$ and $\mathbf{2 b}$ in Figure 4) due to steric hindrance to stop the free rotation of $\mathrm{N}-\mathrm{C}$ bond. Minimized Energy in the ChemBio 3D Ultra Software analyzed the relative configuration of the four stereoisomers suggested that only $\mathbf{1 a}$ and $\mathbf{1 b}$ conformed to the analysis of NOED spectra. In the $\mathbf{1} \mathbf{a}$ and $\mathbf{2} \mathbf{b}$, the distance between $\mathrm{H}-8$ and $\mathrm{H}-13$ were $2.413 \mathrm{~A}$ and $2.828 \mathrm{~A}$, respectively, implying that these two protons were close in space, which also was consistent with the observed NOED spectra. The distance between H-7a and H-13 in $\mathbf{1 a}$ and $\mathbf{2 b}$ were $3.900 \mathrm{~A}$ and $2.766 \mathrm{~A}$, respectively. In the NOED spectra, the correlation of $\mathrm{H}-7 \mathrm{a}$ and $\mathrm{H}-13$ was not observed, which demonstrated these two protons were in long distance, and this implied that the relative configuration of $1 \mathrm{a}$ (3.900A between $\mathrm{H}-7 \mathrm{a}$ and $\mathrm{H}-13)$ was more correct than that of $2 \mathbf{b}(2.766 \mathrm{~A})$. In the same way, the relative configuration of $\mathbf{2}$ was determined to be $\mathbf{1 b}$ not $\mathbf{2 a}$ owing to the absent correlations between $\mathrm{H}-7 \mathrm{~b}$ and $\mathrm{H}-13$ in the NOED spectra. Thus, the relative configurations of 1 and 2 were determined.

The known compound (5) was determined to be $N$-formyl-Ltyrosine methyl ester based on the NMR, MS data and optical rotation $[\alpha]_{\mathrm{D}}^{22}=+200.7(c=0.05$, methanol), which was known as a synthetic compound but never an isolated natural specimen. ${ }^{7}$

From the view of biosynthesis, compounds $\mathbf{1}$ and $\mathbf{2}$ might be originated from a PKS-NRPS hybrid pathway, which implied the same amino acid origin (L-tyrosine) as that of compound 5. Thus, the stereochemistry of C-8/C-13 in $\mathbf{1}$ and $\mathbf{2}$ were suggested to be $R / / R$ and $R / S$, respectively.

Trichodenol A (3) was isolated as colorless oil, $[\alpha]_{\mathrm{D}}^{22}=-214.4$ $(c=-0.01$, methanol). The molecular formula of this compound was established as $\mathrm{C}_{14} \mathrm{H}_{20} \mathrm{O}_{5}$ (5 degrees of unsaturation) on the basis of HRESI MS $\left(m / z\right.$ 291.1204 $\left.[\mathrm{M}+\mathrm{Na}]^{+}\right)$. The ${ }^{1} \mathrm{H},{ }^{13} \mathrm{C}$ NMR and HMQC NMR spectra data of 3 (Table 2) revealed a methyl, four methylene units, two methines, a carbonyl group and one para-substituted phenyl ring. These data accounted for all the ${ }^{1} \mathrm{H}$ and ${ }^{13} \mathrm{C}$ NMR resonances of 3. Interpretation of the ${ }^{1} \mathrm{H}-{ }^{1} \mathrm{H}$ COSY NMR data of 3 identified three isolated proton spin systems corresponding to the C-2(C-6)-C-3 (C-5), C-7-C-8, and C-10-C-11-C-12(12-OH)-C-13(13-OH)-C-14 fragments (Figure 2). The remaining connection was solved by HMBC correlations. The correlations of $6-\mathrm{OH}$ with C-6 displayed that this hydroxyl group was attached at C-6. The fragment of C-7-C-8 was connected at C-1 supported by the correlation of $\mathrm{H}-7$ with $\mathrm{C}-1, \mathrm{C}-2$ and C-6. The correlations from $\mathrm{H}_{2}-10$ and $\mathrm{H}_{2}-11$ to $\mathrm{C}-9$ revealed the presence of 4,5-dihydroxyhexanoic ester moiety. The cross peak of $\mathrm{H}-8$ with C-9 in the HMBC spectra confirmed that the 5-dihydroxyhexanoic ester moiety was connected with C-8. Thus, the planar structure of $\mathbf{3}$ was determined. Modified Mosher's reaction
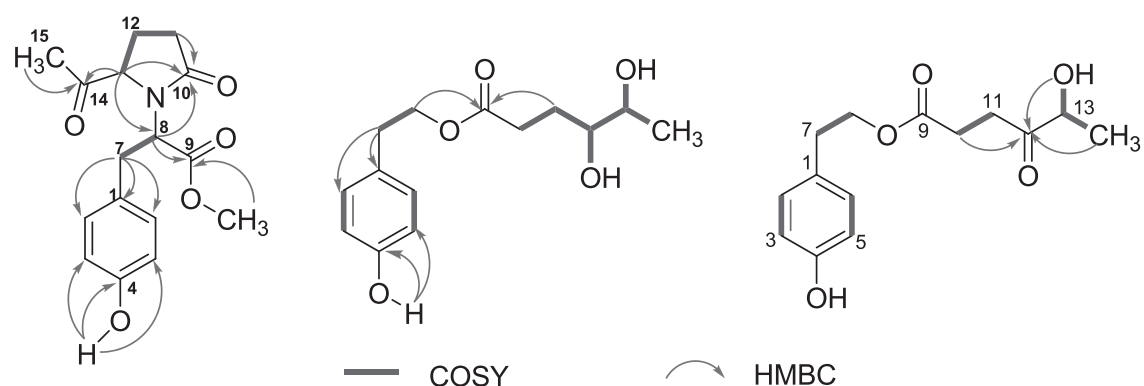

Figure $3{ }^{1} \mathrm{H}_{-}{ }^{1} \mathrm{H}$ COSY and key $\mathrm{HMBC}$ correlations for compounds 1,3 and 4 . A full color version of this figure is available at The Journal of Antibiotics journal online. 
<smiles>COC(=O)[C@H](Cc1ccc(O)cc1)N1C(=O)CC[C@H]1C(C)=O</smiles>

$1 a$<smiles>COC(=O)[C@H](Cc1ccc(O)cc1)N1C(=O)CC[C@H]1C(C)=O</smiles>

1b<smiles>COC(=O)[C@@H](Cc1ccc(O)cc1)N1C(=O)CC[C@H]1C(C)=O</smiles>

2a<smiles>COC(=O)[C@H](Cc1ccc(O)cc1)N1C(=O)CC[C@H]1C(C)=O</smiles>

2b
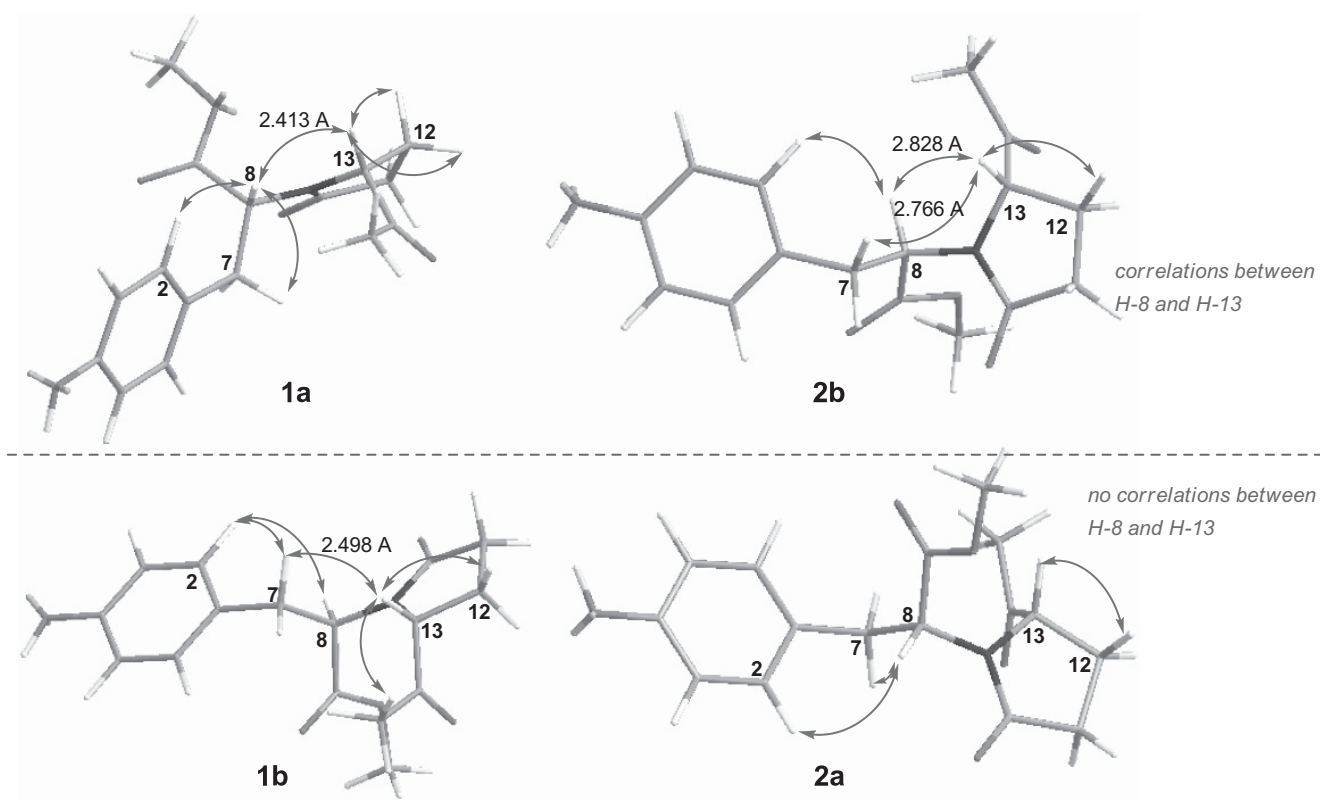

$2 b$
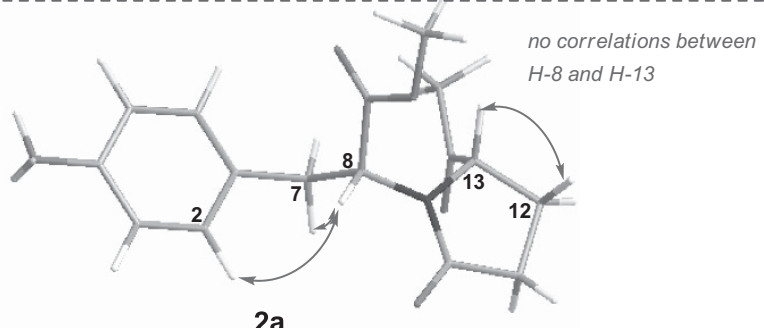

$\mathrm{H}-8$ and $\mathrm{H}-13$

Figure 4 NOED analysis and Minimized Energy of $\mathbf{1}$ and $\mathbf{2}$ by ChemBio Ultra 11.0. A full color version of this figure is available at The Journal of Antibiotics journal online.

Table $2{ }^{1} \mathrm{H}(600 \mathrm{MHz})$ and ${ }^{13} \mathrm{C}$ NMR (150 MHz) spectroscopic data (DMSO- $d_{6}$ ) of trichodenols A (3) and B (4)

\begin{tabular}{|c|c|c|c|c|}
\hline \multirow[b]{2}{*}{ Pos. } & \multicolumn{2}{|c|}{ Trichodenol A (3) } & \multicolumn{2}{|c|}{ Trichodenol B (4) } \\
\hline & $\delta_{H}(\mathrm{~J}$ in $\mathrm{Hz})$ & $\delta_{C}$, mult. & $\delta_{H}(J$ in $H z)$ & $\delta_{c}$, mult. \\
\hline 1 & - & $128.4, \mathrm{~s}$ & - & $127.8, \mathrm{~s}$ \\
\hline 2 & $7.03, d(8.4)$ & 130.2, d & $7.02, d(8.4)$ & 129.7, d \\
\hline 3 & $6.69, d(8.4)$ & $115.6, d$ & $6.68, d(8.4)$ & $115.1, d$ \\
\hline 4 & - & 156.3, s & - & $155.8, \mathrm{~s}$ \\
\hline 5 & $6.69, d(8.4)$ & $115.6, d$ & $6.68, d(8.4)$ & $115.1, d$ \\
\hline 6 & $7.03, d(8.4)$ & $130.2, \mathrm{~d}$ & 7.02, d (8.4) & 129.7, d \\
\hline 7 & $2.76, \mathrm{t}(7.2)$ & $34.1, \mathrm{t}$ & $2.74, \mathrm{t}(7.2)$ & $33.5, \mathrm{t}$ \\
\hline 8 & $4.14, \mathrm{~m}$ & $65.1, \mathrm{t}$ & $4.12, \mathrm{t}(7.2)$ & $64.8, t$ \\
\hline 9 & - & 173.6, s & - & $172.2, \mathrm{~s}$ \\
\hline $10 a$ & $2.28, \mathrm{~m}$ & $30.9, \mathrm{t}$ & $2.78, \mathrm{dd}(13.2,6.6)$ & $31.9, \mathrm{t}$ \\
\hline $10 \mathrm{~b}$ & $2.39, \mathrm{~m}$ & - & $2.81, \mathrm{dd}(13.2,6.6)$ & - \\
\hline $11 \mathrm{a}$ & $1.45, \mathrm{~m}$ & $27.8, \mathrm{t}$ & $2.45, \mathrm{t}(6.6)$ & $27.2, \mathrm{t}$ \\
\hline $11 \mathrm{~b}$ & $1.65, \mathrm{~m}$ & - & - & - \\
\hline 12 & $3.18, \mathrm{~m}$ & $73.8, \mathrm{t}$ & - & $212.6, \mathrm{~s}$ \\
\hline 13 & $3.45, \mathrm{~m}$ & $69.6, \mathrm{t}$ & 4.03, m & $72.1, \mathrm{t}$ \\
\hline 14 & $0.99, d(6.6)$ & 19.0, q & $1.16, \mathrm{~d}(6.6)$ & $19.5, q$ \\
\hline $4-\mathrm{OH}$ & $9.22, \mathrm{~s}$ & - & $9.19, \mathrm{~s}$ & - \\
\hline $12-\mathrm{OH}$ & $4.39, d(5.4)$ & - & - & - \\
\hline $13-\mathrm{OH}$ & $4.35, d(4.8)$ & - & $5.35, \mathrm{~d}(5.4)$ & - \\
\hline
\end{tabular}

was tried to determine the absolute configuration of $\mathrm{C}-12$ or $\mathrm{C}-13$, whereas the reaction was not succeeded, and this might be the steric hindrance of the diol at $\mathrm{C}-12$ and $\mathrm{C}-13$ to preclude the reaction to happen.

Trichodenol B (4) was isolated as colorless oil, $[\alpha]_{\mathrm{D}}^{22}=-159.6$ ( $c=-0.01$, methanol). The molecular formula of this compound was determined to be $\mathrm{C}_{14} \mathrm{H}_{18} \mathrm{O}_{5}$ on the basis of HRESI MS $(\mathrm{m} / z 289.1052$ $[\mathrm{M}+\mathrm{Na}]^{+}$) with one more degree of unsaturation than that of 3 . The NMR data revealed that compound 4 also had the same moiety of 4-(2-hydroxyethyl) phenol as found in 3. Analysis of the ${ }^{13} \mathrm{C} N M R$ confirmed that 4 had one more keto group and one less oxymethine unit than that of 3 , which implied that C-12 or C-13 was further oxygenated to be a keto group. The $\mathrm{HMBC}$ correlation from $\mathrm{CH}_{3}-14$, $\mathrm{H}-13$ and $13-\mathrm{OH}$ to $\mathrm{C}-12$ confirmed that $\mathrm{C}-12$ was oxygenated to the corresponding keto group. The modified Mosher's reaction was also not successful to determine the absolute configuration of C-13.

The putative biosynthesis of compounds 1 and 2 was suggested in the Figure 5.

Compounds 1-5 were evaluated for cytotoxic activity against several cancer cell lines including A549, MDA-MB-231 and PANC-1 with $\mathrm{IC}_{50}$ value more than $100 \mu \mathrm{m}$ (the $\mathrm{IC}_{50}$ value of positive control 5-fluorouracil were $0.47,012$ and $0.67 \mu \mathrm{M}$, respectively).

Our previous research about this endophytic fungus found a series of cytochalasans with different amino acid (Val and Leu) and diverse carbon skeletons. $^{2-6}$ The new compounds obtained in this note with 
<smiles>CO[C@H](Cc1ccc(O)cc1)[C@@H](Cc1ccc(O)cc1)N1C(=O)CCC1C(C)=O</smiles>

Figure 5 The putative biosynthesis of compounds 1 and 2 .

Tyr origin further enhance that the endophytic fungi inhabiting unique environment could produce many secondary metabolites with a wide range of structural characteristics.

\section{ACKNOWLEDGEMENTS}

We thank Syngenta for the fellowship to L Chen. We gratefully acknowledge financial support from Program for Innovative Research Team in IMPLAD (PIRTI), the Open Funding Project of the State Key Laboratory of Bioactive Substance and Function of Natural Medicines, PUMC Youth Fund and the Fundamental Research Funds for the Central Universities, and the Chinese National S\&T Special Project on Major New Drug Innovation (2011ZX09307002-01).
1 Kennnedy, J. P. et al. Application of combinatorial chemistry science on modern drug discovery. J. Comb. Chem. 10, 345-354 (2008).

2 Chen, L. et al. Stereochemical determination of new cytochalasans from the plant endophytic fungus Trichoderma gamsii. Fitoterapia 96, 115-122 (2014).

3 Ding, G. et al. Trichalasins C and D from the plant endophytic fungus Trichoderma gamsii. Fitoterapia 83, 541-544 (2012).

4 Ding, G. et al. Cytochalasans with different amino-acid origin from the plant endophytic fungus Trichoderma gamsii. J. Antibiot. 65, 143-145 (2012).

5 Ding, G. et al. Trichoderones A and B: two pentacyclic cytochalasans from the plant endophytic fungus Trichoderma gamsii. Eur. J. Org. Chem. 13, 2516-2519 (2012).

6 Ding G. et al. Trichodermone, a spiro-cytochalasan with a tetracyclic nucleus $(7 / 5 / 6 / 5)$ skeleton from the plant endophytic fungus Trichoderma gamsii. J. Nat. Prod. 77, 164-167 (2014)

7 Konda, M. et al. Amino acids and peptides. XVIII. A biogenetic-type, asymmetric synthesis of (S)-reticuline from L-3-(3,4-dihydroxyphenyl)-alanine by 1,3-transfer of asymmetry. Chem. Pharm. Bull. 23, 1063-1075 (1975).

Supplementary Information accompanies the paper on The Journal of Antibiotics website (http://www.nature.com/ja) 